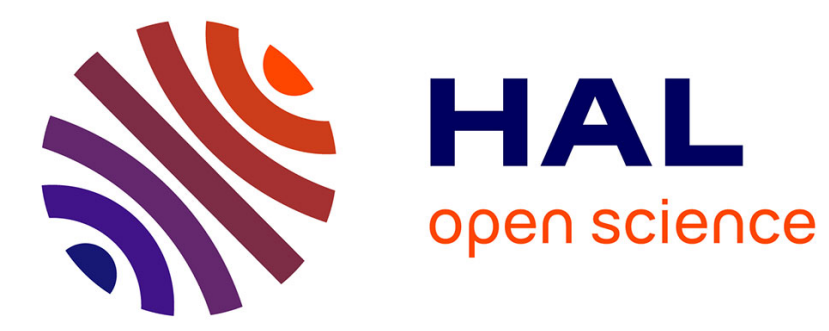

\title{
Les collocations en russe : combinabilité et restrictions
}

Vladimir Beliakov

\section{To cite this version:}

Vladimir Beliakov. Les collocations en russe: combinabilité et restrictions. Revue des études slaves, 2012, LXXXXIII (2-3), pp.373-386. hal-00955193

\section{HAL Id: hal-00955193 \\ https://hal-univ-tlse2.archives-ouvertes.fr/hal-00955193}

Submitted on 4 Mar 2014

HAL is a multi-disciplinary open access archive for the deposit and dissemination of scientific research documents, whether they are published or not. The documents may come from teaching and research institutions in France or abroad, or from public or private research centers.
L'archive ouverte pluridisciplinaire HAL, est destinée au dépôt et à la diffusion de documents scientifiques de niveau recherche, publiés ou non, émanant des établissements d'enseignement et de recherche français ou étrangers, des laboratoires publics ou privés. 


\section{Vladimir BELIAKOV}

UMR 5263, Cognition, Langue, Langages, Ergonomie

CNRS / Université de Toulouse II Le Mirail

\section{LES COLLOCATIONS EN RUSSE : COMBINABILITE ET RESTRICTIONS}

\section{Introduction}

L'étude appliquée des expressions contraintes est le thème de recherche que nous nous assignerons dans ce travail. Si les recherches sur les séquences figées se sont développées aussi bien en France qu'en Russie, l'intérêt pour les séquences semi-figées, appelées communément collocations, n'a connu un essor comparable que depuis peu. Un des buts de notre article est donc de contribuer à une meilleure connaissance d'une problématique encore souvent méconnue et d'esquisser une analyse d'inspiration sémantique des phénomènes collocatifs. ${ }^{1}$

Nous commencerons notre examen par une brève présentation des collocations métaphoriques et celles à verbe support. Nous nous intéresserons par la suite à la question de la motivation de ces associations lexicales et tenterons de fournir une description de la relation sémantique liant leurs constituants en concentrant notre réflexion essentiellement sur les constructions lexicales binaires, i.e. composées de deux éléments. Deux aspects de la combinatoire lexicale seront ici traités : le mécanisme qui l'autorise - la combinabilité - et le mécanisme qui la filtre - la restriction.

Suivant I. Mel'čuk, nous considérerons l'expression $A B$ ayant le sens ' $S$ ' en tant que collocation si les trois conditions suivantes sont simultanément remplies :

1. 'S' $\supset$ 'A',

2. A est sélectionné par le locuteur de façon régulière et non contrainte,

3. B n'est pas sélectionné de façon régulière et non contrainte, mais en fonction de A et du sens 'S' à exprimer (Mel'čuk $2003: 23$ ). ${ }^{2}$

\footnotetext{
${ }^{1}$ Pour plus de détails sur les collocations, cf. Beliakov 2011.

2 Dans la terminologie de I. Mel'čuk, «X $\mathrm{X} Y$ Y signifie que l'ensemble X inclut l'ensemble Y comme son sousensemble (cf. Mel'čuk 2003).
} 
Autrement dit, les collocations sont formées du constituant sémantiquement autonome choisi librement par le locuteur en fonction de son sens, appelé la base, et du constituant restreint choisi pour exprimer un sens donné en fonction de la base, appelé le collocatif. ${ }^{3}$

Considérons maintenant les collocations métaphoriques et les collocations à verbe support. ${ }^{4}$

\section{Les collocations métaphoriques}

Les collocations métaphoriques reposent sur le principe cognitif permettant d'appréhender un phénomène sous l'angle d'un autre. ${ }^{5}$ Plusieurs domaines référentiels servent à leur formation. Ainsi, certaines tournures relèvent de la perception humaine. La structuration détaillée et facilement compréhensible fait de ce champ métaphorique une source privilégiée exploitée par la langue. Le transfert métaphorique est à l'origine des séquences qui renvoient à

- la sensation visuelle: блестнула молния => блестнула надежда, блестнула догадка, блестящий предмет => блестящиий ум, блестящий ученый, мутная вода => мутное сознание, мутная тоска, прозрачный бульон => прозрачные звуки, прозрачный бюджет, светльй пиджак => светлая память, светлая голова, темная улииа => темные дела, тёмная девушка, тёмное ичарство, тёмная сторона Интернета ;

- la sensation auditive : громкий звук => громкое имя, громкие слова, тихий звук => тихое очарование, тихая заводь, тихое вино, ${ }^{6}$ эхо выстрела => эхо прессы, эхо войны, эхо культуры ;

\footnotetext{
${ }^{3}$ Cf. Hausmann 1979.

${ }^{4}$ Parmi d'autres types de séquences semi-figées, notons les collocations ayant la fonction MAGN dont le collocatif, adjectif en règle générale, exprime le sens «très, » «intense », « à un degré élevé »: жzyчuй брюнет, закадычный друг, заклятый враг, закоренельй преступник, проливной дождь, etc., ou bien les collocations périphrastiques dont la particularité réside dans le fait qu'elles substituent une unité monolexicale et renvoient au même référent que celle-ci. On peut considérer alors qu'une expression est une collocation périphrastique si elle réunit trois éléments: l'élément périphrasé, l'élément périphrasant et le prédicat sémantique associé à l'élément périphrasant. Ainsi, dans les expressions черное золото, ияарь тайги оu четвероногий плотник, les éléments périphrasés sont respectivement нефть, кедр, бобер, les éléments périphrasants des expressions sont золото, царь, плотник et les prédicats sémantiques sont черное, тайги, четвероногий.

${ }^{5}$ A l'intérieur des collocations métaphoriques, le siège de la métaphore est le collocatif.

${ }^{6}$ Ce terme désigne les vins non mousseux : Винодель часто используют термин "тихие вина". Это означает, что в отличие от шампанского они не содержат углекислоту. К тихим относятся столовые сухие, полусухие, полусладкие, креплёные и десертные (Это полезно, «Даша», № 10, 2004).
} 
- la sensation gustative : горький огурец => горькая радость, горький упрек, кисльее ягоды => кислая ульбка, кислое выражение лица, пресное тесто => пресная щутка, пресный человек, пресное благополучие, приторная пища => приторная ульбка, приторный лесть, приторная болтовня, соленая рыба => соленая шутка, соленый анекдот, сладкий чай => сладкая речь, сладкая женщина, сладкая тоска ;

- la sensation tactile : гладкая кожа => гладкие отношения, гладкое исполнение, жесткое кресло => жесткая позиция, жесткие сроки, жесткие меры, мягкая постель => мягкий человек, мягкий характер, мягкий упре, твердый камень => твердый характер, твердая позищия, твёрдая ставка, горячий суп => горячая пора, горячий привет, горячий защитник, холодная вода $=>$ холодный человек, холодный взгляд, холодный ум ;

- la sensation olfactive : аромат сирени => аромат новизны, предреволюиионный аромат, аромат прошлого смрад дыма => смрад роскоши, смрад клеветы, смрад войныл.

Par ailleurs, à l'intérieur des associations collocatives, le transfert métaphorique se produit entre les domaines tels que :

1. Monde physique $=>$ Monde humain qui concerne entre autres :

a. L'activité psychique et émotionnelle de l'homme, dont notamment

- la pensée : россыпи мыслей, туман заблуждений, свалка идей, мусор в голове, обрывки мыслей, калейдоскоп мыслей ...

- les émotions et les sentiments : огонь любви, дуновение страсти, кипение страстей, вихрь чувств, порыв любви, водопад эмочий, буря гнева, чаша скорби, пучина страха ...7

- l'élocution : град реплик, русло беседы, мозаика слов, ручеек разговора, словесный понос ...8

\footnotetext{
${ }^{7}$ Notons que les phénomènes naturels tels que l'eau, le feu, le froid, le vent, la lumière servent fréquemment de pivot métaphorique dans la présentation des émotions et des sentiments humains. Par exemple : чувства / страсти кипят, капля уважения / любви, облить презрением, прилив чувств, водоворот чувств, чувства нахлььнули, купаться в радости, радость испарилась, чувства бьют ключом, жажда мести, пламя любви, разжечь ненависть, пожар страстей, чувства угасти, страх леденит, холодный взгдяд, буря страстей, ураган ненависти, радость осветила его личо, сиять от счастья, луч надежды, грусть омрачила, etc.
} 
b. Les catégories sociales : задворки истории, хлам прошлого, метастазы коррупции, социиальные пружины, рогатки цензуры, маяк производства, потолок зарплаты, преддверье революиии, судебная машина, рычаги войны, магистраль прогресса ...

c. Les rapports humains et les valeurs morales : лабиринт отношений, тень недоверия, паутина ненависти, стена равнодушия, стрель злобы, мрак порока, воздух свободы, пик славы, хомут брака, сеть интриг, цепи насилия ...

2. Monde animal => Monde humain : когти страха, джунгли города, духовная спячка, логово врага, муравейник толпы, табун туристов, хвост очереди, свора хулиганов, щупальца рук, грива волос ...

3. Monde physique => Monde physique : водопад света, водопад звуков, пучина огня, стена огня, море ржи, русло улищы, алмазы росы, струя песка, лента дороги, бархат травы, сеть дождя, скатерть снегов, колодец Вселенной, нить времени ...

Du point de vue sémantique, le collocatif marque à travers le procédé métaphorique

- une grande quantité ou une petite quantité : бездна насилия, куча забот, туча сплетен, океан жизни, море крови, гора дел, вагон неприятностей, букет болезней, воз проблем, лес рук, поток писем, лавина исследований ; капля жалости, крохи счастья, крупинка мудрости, горстка людей ...

- les éléments organisationnels : фундамент благополучия, фундамент знаний, структура управления, структура общества, политическая структура, стержень исследования, нравственный стержень, стержень человека; остов нравственности, остов произведения, остов рекламы ; строй мышления, строй души, строй мислли ...

- l'enchaînement ou la durée : цุепь событий, цепочка фактов, гряда дней, гряда праздников, гряда выступлений ; ряд поколений, ряд исключений, ряд случаев ; линия поведения, линия жизни, сюжетная линия; полоса неудач, полоса забастовок, полоса процветания ...

- la direction : магистраль прогресса, магистраль жизни, магистраль политики, тропа любви, тропа исканий, житейская дорога, дорога ичивилизации, дорога

\footnotetext{
${ }^{8}$ N. D. Arutjunova souligne que notre monde intérieur se construit par analogie au monde extérieur. Par conséquent, le lexique qui relève du monde physique, matériel utilisé dans le sens métaphorique sert de source principale pour caractériser l'état psychique et émotionnel de l'homme. Elle écrit notamment: «Поскольку внутренний мир человека моделируется по образцу внешнего, материального мира, основным источником психологической лексики является лексика «физическая», используемая во вторичных, метафорических смыслах» (Арутюнова 2009 : 95).
} 
прогресса, дорога к знанию, идти прямой дорого ; творческий путь, ложный путь, путь реформ ...

- le début, la source : зародыш будущего, зачаток добра, зачатки отномений, исток деятельности, источник счастья, источник благополучия, росток культуры, кольюбель револючии, корень зла, корень ошибок ...

- la fin, la limite : кульминационная точка, критическая точка, венеи развития, венеч творчества ...

- le désordre : винегрет мыслей, винегрет иџитат, каша машин, каша доходов и расходов, окрошка стилей, окрошка выступлений, клубок чувств, клубок противоречий, лабиринт событий, лабиринт идей ...

A l'instar des unités lexicales, les collocations métaphoriques représentent un phénomène systémique que l'on relève au niveau des relations :

- $\quad$ synonymiques : бархат кожи - атлас кожи, вихрь чувств - буря чувств - шквал чувств, вставить реплику - вклинить реплику - втиснуть реплику...

- antinomiques : вихрь чувств - дуновение чувств, вспыхнул гнев - угас гнев, горячий прием - холодный прием, пресная шутка - соленая шутка, мягкость характера - твердость характера, море счастья - капля счастья ...

- dérivationnels : собачий холод, присобачить объявление, насобачиться в деле; человек скис, идеи прокисли, кислое лицо, кислятина фраз ; гнев кипит, обида вскипела, раздражение выкипело, толпа закипела, подкипятить злобу ...

Un autre fait qui témoigne de l'organisation systémique des séquences semi-figées est leur polysémie. Par exemple : ветер съел камень, изолячия съедает шум, съесть конкурента, съесть упреками, его съела болезнь, покупка съела все деньги, ревность съедает. La polysémie des collocations reflète les glissements sémantiques à partir du sens propre vers les sens métaphoriques. Ainsi, si l'on examine, à titre d'exemple, les collocations avec le verbe течь, on constatera que le sens figuré le plus proche du sens propre вода течет est celui de la séquence песок / зерно течет, car il s'agit du transfert métaphorique objet $=>$ objet. On passe ensuite au transfert objet $\Rightarrow>$ substance : воздух / аромат течет. La transposition monde physique => monde humain : толпа mечеm représente un autre degré du procédé métaphorique. Et enfin, l'abstraction métaphorisante donne lieu à une relation de similitude entre le monde concret et le monde abstrait : monde physique $=>$ monde psychique $/$ monde social : мысли текут, жизнь течет, время течет, etc. 
Toutefois, étant donné que la matière sémantique des mots, y compris les unités polylexicales, est une structure complexe, on ne peut pas présenter les sens métaphoriques des collocations comme un ensemble organisé de façon linéaire (cf. schéma 1) :

Schéma 1.

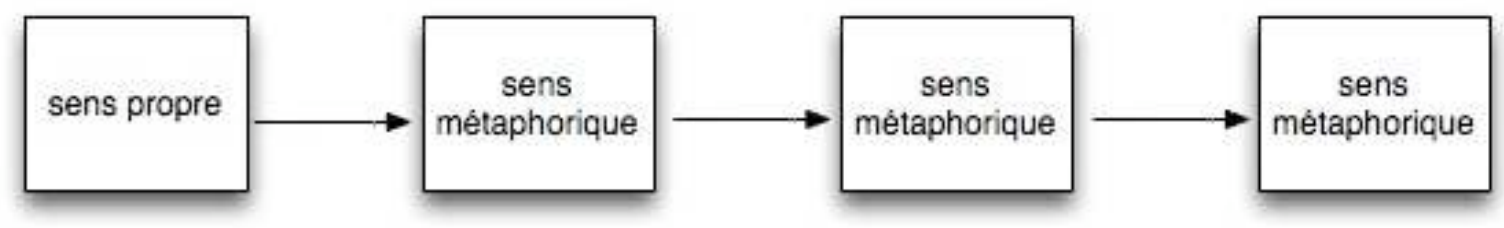

Il nous semble plus approprié de représenter la polysémie des séquences semi-figées sous forme de constellation dont une illustration est proposée dans le schéma 2.

Schéma 2.

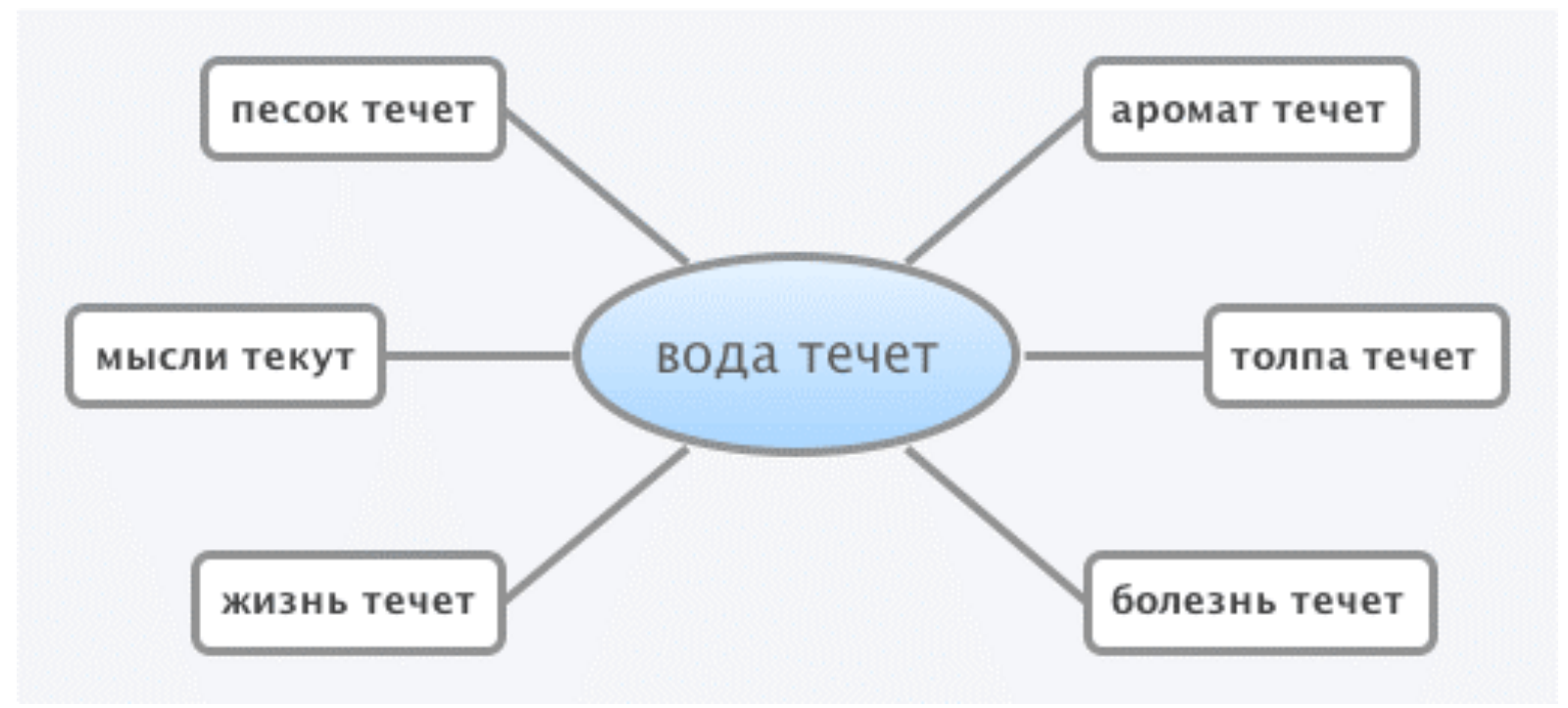

\section{Les collocations à verbe support}

La fonction principale du verbe qui apparaît dans ces collocations consiste à servir de support syntaxique au nom qui exprime un prédicat sémantique. ${ }^{9}$ Plusieurs propriétés caractérisent ce

\footnotetext{
${ }^{9}$ Dans le cadre de la théorie Sens<=>Texte d'I. Mel'čuk, on répartit les verbes supports en fonction de leurs relations syntagmatiques et le rôle syntaxique que le mot-clé joue par rapport à cette relation. Ainsi, les verbes supports ayant la fonction Oper relient les actants du mot-clé en tant que sujet grammatical avec le mot clé en tant que complément : заявление X- $a$ - X делает заявление $=X$ заявляет $\left(\right.$ Oper $_{1}$ (заявление) $=$ делать). Les
} 
type de constructions. D'abord, on peut facilement les remplacer par les verbes liés morphologiquement aux noms supportés. Comparons : вести атаку = атаковать, вести поиски = искать, давать разрешение = разрешать, оказывать воздействие =

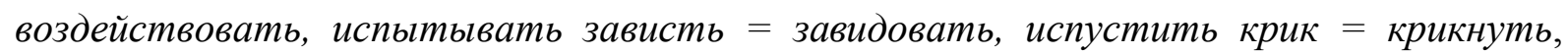
подвергаться старению $=$ стареть, давать совет $=$ советовать, совершить взлет $=$ взлететь, сделать заявление = заявить, etc. Alors que la substitution de l'expression par un verbe n'est pas possible pour d'autres types de constructions contraintes. Ainsi, parmi les séquences делать вызов еt бросить вызов, seule la première est commutable avec le verbe вblзыlвать. Comparons :

сделать вызов врача на дом = вызвать врача на дом

сделать вызов оператора $=$ вызвать оператора

сделать вызов по телефону = вызвать по телефону

бросить вызов судьбе $\neq$ ?вызвать судьбу

бросить вызов болезни $\neq$ вызвать болезнь

бросить вызов врагам $\neq$ вызввать врагов

En effet, le syntagme бросить выззо est une collocation métaphorique dont la formation est fondée sur un mécanisme sémantique différent.

Ensuite, le verbe support peut être effacé sans que la construction perde son sens. Cette propriété est essentielle pour la définition des collocations à verbes supports. Par exemple :

Офииер дал приказ солдатам. Приказ офицера солдатам.

Анна оказала услугу Ивану. Услуга Анны Ивану.

Анна произвела перепланировку квартиры. Перепланировка квартиры Анной.

Батарея ведет обстрел противника. Обстрел противника батареей

En revanche, l'effacement d'un verbe prédicatif dans une association lexicale libre supprime automatiquement le sens de la phrase, puisqu'il ne reste qu'une succession des substantifs correspondant, dans le cas d'un prédicat verbal, à ces arguments :

Иван ведет машину

Петя сделал упражнение.

Игорь дал книгу Маше.
*Иван машина / ?машина Ивана

* Петя упражнение / ?упражнение Пети.

*Игорь книга Маша / ?книга Игоря Маше.

verbes Labor relient le premier actant du mot clé en tant que sujet avec le deuxième actant et le mot clé en tant que compléments : обстрел $Y-a X-о м-X$ подвергает $Y-a$ обстрелу $=X$ обстреливает $Y-a$ (Labor 2 (обстрел) = подвергать). Les verbes Func relient le mot clé en tant que sujet avec ses actants en tant que compléments : обстрел $Y$-а производится $X$-ом (Func (обстрел) = производиться). (Pour plus de détails, cf. Mel'čuk, Clas, Polguère 1995, Иорданская, Мельчук 2007, Апресян 2008). 
Et enfin, on peut utiliser le critère de co-occurrence compatible afin de démontrer la différence du sens du même verbe en tant que verbe support et verbe distributionnel. Selon ce critère, s'il y a la possibilité de construire une phrase à co-occurrence compatible pour un lexème donné, il s'agit alors d'une seule acception de ce lexème. Si ce n'est pas le cas, ce critère sera sans effet. ${ }^{10}$ Ainsi, les phrases à co-occurrence compatible pour les verbes sémantiquement pleins давать, делать et производить sont par exemple : Петя дал книгу, ручку и тетрадь Маше. Плотник сделал пол и крышу за день. Завод производит станки и детали. La coordination est également légitime au sein des séquences collocationnelles : Петя давал советы и обещуания. Он сделал выстрел и бросок в сторону. Техники произвели осмотр и перепланировку. En revanche, on ne peut pas coordonner dans le même énoncé des noms sélectionneurs d'un verbe support et les compléments du même verbe employé en tant que verbe prédicatif dans un syntagme non contraint. Comparons :

?Петя дал книгу, ручку и разрешение Маше.

\section{?Плотник сделал пол и заявление.}

\section{?Рабочий производит детали и осмотр помещения.}

Il en résulte que давать делать et производить n'ont pas le même sens dans les associations lexicales libres et dans les constructions contraintes.

Traditionnellement, on regroupe les noms prédicatifs constitutifs des collocations à verbes support en quatre classes sémantiques :

- les noms d'actions : сделать шаг, дать совет, совершить убийство, оказать поддержку, оказать влияние, подвергать обстрелу ...

- les noms d'activités humaines : вести спор, вести борьбу, вести наблюдение, вести поиски ...

- les noms de procès : подвергаться обесиениванию, подвергаться облучению, претерпевать изменения, претерпевать деформащию ...

- les noms d'états : испытывать ненависть, испьтывывать нужду, испьтывывать мучения, питать уважение, питать презрение ... ${ }^{11}$

\footnotetext{
${ }^{10}$ Cf. Melcuk, Clas, Polguère $1995: 64$.

${ }^{11}$ Cf. Apresjan 2008. E. V. Padučeva, quant à elle, classe les noms d'actions parmi les noms de procès. La linguiste russe relève également les noms d'événements qui se combinent avec les verbes ayant le sens «se passer, avoir lieu », les noms d'états qui s'associent aux verbes ayant les sens «être dans en état», "se mettre dans un état / cesser d'être dans un état », « mettre qqn. dans un état » et les noms de qualités co-occurrents des verbes ayant le sens «posséder, se caractériser, se distinguer». Elle écrit notamment: «Все имена ПРОЦЕССОВ допустимы в контексте глаголов со значением 'протекать', 'идти', т. е. 'иметь место'. [...]
} 
Tous ces noms sont des lexèmes à sens prédicatif qui implique nécessairement des participants et réunit donc d'autres sens en des configurations sémantiques. ${ }^{12}$

Dans la perspective syntaxique, le caractère «soudé » des collocations à verbe support, conduit certains linguistes à les traiter comme une sorte de verbe complexe, fonctionnant syntaxiquement comme un seul mot. Le groupe VN ne différerait donc pas d'un verbe simple et aura un comportement syntaxique équivalent.

Le développement qui va suivre essaiera de répondre à la question de savoir quelle est l'incidence de la sémantique du collocatif et de la base sur leurs aptitudes combinatoires.

\section{La combinabilité et les restrictions combinatoires}

Rappelons qu'une des caractéristiques pertinentes des séquences contraintes est leur sens global qui n'équivaut pas à la somme des acceptions de leurs constituants. On pourrait alors supposer qu'au sein des associations lexicales semi-figées, les collocatifs se désémantisent. $\mathrm{Au}$ premier abord cette thèse paraît juste. En effet, dans les séquences métaphoriques avec les noms de vents, le collocatif fonctionne comme opérateur d'intensité : шквал гнева = очень сильный гнев, вихрь перемен = сильные, резкие перемень ; буря протестов $=$ очень сильные протесты, ураган рукоплесканий = очень сильные рукоплескания. A l'intérieur des collocations métaphoriques avec les quantifieurs lexicaux les collocatifs expriment une idée de grande ou petite quantité du référent désigné par la base et remplissent ainsi la même fonction que les quantifieurs grammaticaux : поток людей, куча людей, прорва людей, лавина людей, море людей, гора бумаг, куча бумаг, ворох бумаг, прорва бумаг, вагон

\footnotetext{
Частная разновидность процессов - ДЕЙСТВИЯ, т.е. процессы с активным субъектом и фиксированным пределом, такие как покупка, проверка [...]. Имена действия допустимы в контексте глаголов со значением 'производить', 'вести' [...]. Имена СОБЫТИЙ употребляются в контексте глаголов со значением 'произошло', 'случилось'. События отличаются от процессов тем, что имеют ретроспективного наблюдателя. Имя СОСТОЯНИЯ сочетается а). с глаголом, означающим 'пребывать в данном состоянии' [...], б). с глаголом, обозначающим 'приходить/прийти в данное состояние' и 'выходить/выйти из него' [...], в. с каузативным глаголом, означающим 'привести в данное состояние' и 'вывести из него'. [...] Имена СВОЙСТВ хорошо вписываются в контекст глагола со значением 'обладать, отличаться, характеризоваться'» (Падучева 2009 : 328-332).

${ }^{12}$ Cf. Mel'cuk 1995 : 36. Une relation morphologique avec un verbe n'est pas le critère de prédicativité des substantifs. Il existe des substantifs prédicatifs « autonomes », qui n'ont pas de verbe associé. Autrement dit, un prédicat nominal est défini par le fait qu'il a des arguments et par la nature de ces arguments, et non pas par un lien morphologique avec un prédicat verbal (cf. Gross 1989 : 7-8). Par exemple, aucun verbe ne correspond au nom пощечина. Toutefois, c'est un substantif prédicatif, car il implique des participants : пощечина X-а Y-y.
} 
бумаг, горстка студентов, крохи любви, капля жалости, etc. Quant aux constructions à verbe support, on considère souvent que seul la base est porteur de sens, alors que le verbe ne sert qu'à verbaliser le nom et à exprimer les valeurs purement grammaticales : temps, aspect, mode, réflexivité, personne, nombre, genre, etc. ${ }^{13}$ Ainsi, si les énoncés (a) et (b) avec les verbes осматривать еt ненавидеть et les syntagmes correspondants décrivent les mêmes situations, il s'ensuit que les verbes производить, делать, испытыввать, питать et относиться n'apportent aucun sens nouveau et sont, par conséquent, sémantiquement vides. $^{14}$

(a) Рабочие осмотрели помещение = Рабочие произвели осмотр помещения = Рабочие сделали осмотр помещения.

(b) Он ненавидит льстецов $=$ Он испытывает ненависть $к$ льстецам $=$ Он питает ненависть кльстеиам = Он относится с ненавистью кльстецам.

Si tel était vraiment le cas, les possibilités de commutation devraient être plus ou moins importantes et les collocatifs seraient substituables dans la plupart d'expressions. On constate toutefois que les noms de vents ne sont pas toujours interchangeables à l'intérieur de collocations, que diverses bases sélectionnent les quantifieurs lexicaux différents et que certaines collocations à verbe support sont légitimes, alors que d'autres ne sont pas acceptables. Comparons :

шквал писем - ?метель писем

буря гнева - ?смерч гнева

ураган эмоций - ?ураган солдат

град камней - ?ворох камней

лес рук - ?бездна рук

туча комаров - ?груда комаров

вести атаку - ?делать атаку

давать команду - ?производить команду

\footnotetext{
${ }^{13}$ Citons M. Gross, I. Mel'čuk et E. V. Padučeva : «[...] les verbes supports sont des mots grammaticaux non porteurs de sens. [...] leur rôle consiste à restructurer syntaxiquement la phrase, sans en changer le sens » (Gross 1998 : 26, 27). «Le premier triplet est formé par les fonctions lexicales Oper, Func et Labor qui formalisent la notion de verbe support [...]. Ces FL et leurs valeurs sont des verbes sémantiquement vides (ou vidés dans le contexte de leur mot-clé) ; elles servent à « verbaliser » les noms prédicatifs (c'est-à-dire les noms dont le sens est un prédicat sémantique), en exprimant le mode et le temps. Le rôle de ces FL est simplement syntaxique [...]» (Mel'čuk, Clas, Polguère $1995:$ 138). [...] сочетания отпредикатных имен с глаголами - это по существу эквиваленты слова: одержал победу = победил (Падучева $2009: 53$ ).

${ }^{14}$ Cf. Апресян $2004: 5$.
} 
подвергаться старению - ?испытывать старение, etc.

Il semble alors que les restrictions combinatoires qui affectent les unités lexicales dans les séquences semi-figées sont fonction de la compatibilité des propriétés de leurs référents qui servent de pivots de transferts métaphoriques dans la langue, ainsi que du contenu sémantique des collocatifs et de celui des bases. Pour étayer notre hypothèse considérons quelques exemples.

Ainsi, les collocations avec l'adjectif каменный s'appuient sur les différentes caractéristiques classifiantes et qualificatives associées au terme камень, notamment неподвижньй, твердый, тяжелый d'où les collocations métaphoriques каменное лицо, каменный человек, каменное слово. En revanche, aucune de ces propriétés ne peut pas être attachée, par exemple, à l'air *каменный воздух, à la poésie *каменная поэзия ou bien à la lumière *каменный свет, de même qu'une pierre ne peut pas être liquide, la fatigue ne peut pas jaillir, un insecte ou un animal ne peut pas couler, une table ne peut pas être profonde, etc., d'où l'impossibilité des séquences: *жидкий камень, *брызнуло утомление, *льется муха, *глубокий стол, еtс.

L'association des collocatifs et des bases peut être déterminée par leur appartenance à la catégorie «animé - inanimé » et plus particulièrement par la caractéristique sémantique « aptitude de se déplacer» propre aux noms d'êtres humains et d'espèces naturelles. ${ }^{15}$ Ainsi, les mots груда, гора et воз dénomment des référents qui ne sont pas censés se mouvoir de façon autonome. Par conséquent, les quantifieurs груда, гора et воз s'associent au sein des collocations aux noms d'objets ou aux noms de référents abstraits, et ne sont pas sélectionnés par les noms d'êtres vivants. Par exemple :

\begin{tabular}{|c|c|}
\hline груда мусора & *груда студентов \\
\hline груда металлолома & * груда кошек \\
\hline гора писем & *гора девушек \\
\hline воз проблем & *воз покупателей \\
\hline
\end{tabular}

De la même manière, les noms d'êtres vivants tels que полчище, стайка, табун, армия ne sont compatibles en tant que collocatifs qu'avec les noms de référents animés ayant une aptitude de se déplacer. Comparons :

$\begin{array}{ll}\text { полчище бюрократов } & \text { *полчище тарелок } \\ \text { стайка туристов } & * \text { стайка стрел } \\ \text { табун любопьтных } & * \text { табун книг }\end{array}$

${ }^{15}$ En effet, les objets inanimés ne peuvent être en mouvement que par le biais d'une force extérieure. 
Le contenu sémantique des termes лавина et поток est inhérente du trait движение. Ces quantifieurs sont alors sélectionnés par les bases désignant des référents censés bouger aussi bien au sens propre qu'au sens figuré, et ne s'associent pas aux noms d'objets statiques. Par exemple :

лавина людей

лавина огня « avalanche de feu »

лавина событий

поток выпускников

поток информациии

поток света ?лавина словарей

?лавина карандашей

?лавина травы

?поток ламп

?поток картин

?поток деревьев

Les quantifieurs ворох et груда servent tous les deux à désigner une grande quantité d'objets en désordre. Toutefois, ils ne sont pas interchangeables dans les associations collocatives. Le terme ворох appartient au même paradigme dérivarionnel que le verbe ворошить dont la définition est двигать, поворачивать, разгребая и сгребая (обычно что-л. рыхлое). Il se combine donc avec les noms d'objets légers qui peuvent facilement être déplacés. Le mot груда quant à lui dénomme une grande quantité d'objets généralement lourds se trouvant en désordre les uns sur les autres. ${ }^{16}$ A l'intérieur des collocations, il s'associe alors aux noms d'objets inutiles ou inutilisés et par conséquent immobiles. Comparons :

ворох тряпья

ворох листьев

ворох простыней

груда железа

груда развалин

груда камней ?ворох стульев

?ворох яблок

?ворох canoг

?груда нужньх документов

?груда полезных книг

?груда срочных бумаг

La signification du terme mуча est constituée des traits classifiants «petites particules » et « dans l'air ». ${ }^{17}$ Ces caractéristiques sémantiques restent manifestes au sein des séquences semi-figées et déterminent la combinabilité du collocatif myчa avec plusieurs bases. Ainsi, le quantifieur myчa s'associe aux noms d'espèces naturelles de petite taille en mouvement dans l'air et n'accepte ni les noms d'autres espèces naturelles ni les noms d'objets. Par exemple : туча комаров ?туча собак

\footnotetext{
${ }^{16}$ Cf. la définition : груда - большое количество каких-л. предметов, сложенных, нагромождённых в беспорядке один на другой.

${ }^{17} \mathrm{Cf}$. la définition : туча - скопление в атмосфере водяных паров или ледяных кристаллов
} 
mуча мух

?туча пауков

туча голубей

?туча самолетов

Par ailleurs, le trait sémantique qualificatif du terme myчa marqué négativement бeдa, опасность, неприятности dérivé du trait dénotatif несущее дождь, град, снег s'ajoute à la sémantique quantitative, donne lieu aux séquences avec les noms dépréciatifs туча проблем, туча неприятностей, туча забот, etc., et bloque la combinaison du collocatif туча avec les mots intrinsèquement appréciatifs : ?mуча радости, ?туча веселья, ?туча счастья, ?туча праздников, alors que ces bases sont compatibles avec d'autres quantifieurs lexicaux : лавина счастья, океан веселья, фонтан радости, куча праздников, еtс.

En ce qui concerne les collocations à verbe support, les noms d'activités humaines tels que спор, борьба, наблюдение, поиски, стрельба, разведка, хозяйство, etc., forment les séquences avec le verbe вести et n'admettent pas d'autres verbes :?делать борьбу, ?делать спор, ?производить наблюдение, ?делать хозяйство, ?совериить поиски. L'explication de cette sélection réside dans la réciprocité du sens du verbe вести «направлять, управлять, двигать чем-л. в определённом направлении » et de la sémantique des noms d'activités qui désignent l'ensemble d'actes ou d'actions humaines hétérogènes et coordonnées ayant un but commun.

Les verbes подвергаться et претерпевать s'associent aux noms de procès. Contrairement au verbe подвергаться, претерпевать n'est pas compatible avec toutes les bases. Ainsi on peut dire подвергаться качке, подвергаться облучению, подвергаться выветриванию, подвергаться обесиениванию, mais plus difficilement ?претерпевать качку, ?претерпевать облучение, ?претерпевать выветривание, ?претерпевать обесиенивание. En effet, la caractéristique sémantique «изменение объекта действия» inhérente au contenu sémantique du verbe претерпевать est à l'origine de sa combinabilité avec les bases qui désignent le changement telles que деформация, изменение, превращчение, мутаџия, еtс.

Le verbe производить est sémantiquement proche du verbe делать. ${ }^{18}$ Par conséquent, les deux lexèmes sont substituables dans un grand nombre de collocations :

производить ремонт = делать ремонт

производить осмотр = делать осмотр

производить выстрел = делать выстрел

производить бросок = делать бросок

\footnotetext{
${ }^{18}$ La première acception du verbe производить est 'сделать, совершить' « faire, accomplir ».
} 
Toutefois производить n'est pas commutable avec делать dans les séquences où le sens propre de ce dernier est plus difficilement perceptible. Notamment, производить ne se combine pas avec les noms de paroles:?производить заявление, ?производить признание, ?производить замечание, alors que ces suites ont un usage régulier avec le verbe делать : делать заявление, делать признание, делать замечание.

Par ailleurs, si certains verbes sont commutables au sein d'une collocation, leur impact sémantique sur le sens de l'expression varie. Ainsi, dans la séquence сделать заключение, le verbe сделать désigne une réalisation d'une action indiquée par le nom prédicatif: совершить какое-л. действие в соответствии со значением существительного. Alors que la collocation прийти к заключению véhicule l'idée d'une longue réflexion, d'une analyse consciente et intentionnée qui aboutit à une conclusion, et ce, grâce au verbe приŭmu utilisé dans un sens métaphorique par référence à sa caractéristique sémantique dénotative достичь места назначения, идя, направляясь куда-л.

\section{Conclusion}

Dans le présent article, notre objectif se réduisait, rappelons-le, à montrer que certaines caractéristiques sémantiques des collocatifs restaient perceptibles au sein des collocations et que ces caractéristiques étaient à l'origine de la combinatoire des éléments dans les séquences semi-figées. Plusieurs faits témoignent en faveur de la thèse avancée.

En effet, les quelques exemples que nous avons examinés nous conduisent à constater que les collocatifs ne se vident pas de leur sens à l'intérieur des séquences semi-figées. Ainsi, contrairement aux déterminants grammaticaux dont le rôle essentiel est exclusivement quantitatif, les quantifieurs lexicaux apportent les paramètres qualitatifs à la catégorie de quantification. C'est en fonction de ces paramètres qualitatifs que les collocatifs quantifieurs sont sélectionnés par les bases.

De même que pour une bonne formation des collocations à verbe support, il faut qu'il y ait une corrélation sémantique entre le verbe support et la base. ${ }^{19}$ Il s'ensuit que le rôle des

\footnotetext{
19 Selon Ju. Apresjan, la corrélation sémantique consiste en redoublement d'une même caractéristique sémantique dans le sens des deux éléments associés : «[...] любое семантическое согласование состоит в повторении какого-то смысла в значениях двух сочетающихся друг с другом элементов » (Апресян 2008 : 35). Cette idée a été également évoquée par E. V. Padučeva : « Описание сочетаемости единиц в тексте, как правило, требует анализа внутреннего устройства этих единиц. Очень часто законы сочетаемости единиц можно свести к необходимости повторения каких-то составных частей этих единиц» (Падучева 2009 : 174).
} 
verbes supports consiste à apporter des précisions sémantiques et à prendre en charge différentes informations que le nom prédicatif n'exprime pas. Dans cette perspective, les verbes supports ont une « fonction sémantique » régulière et descriptible. Cette thèse implique la remise en question de l'idée de l'équivalence entre la construction à verbe support et le verbe distributionnel équivalent.

\section{REFERENCES BIBLIOGRAPHIQUES}

Beliakov V., Les stéréotypes linguistiques en russe: sémantique et combinatoire, Dijon, EUD, 2011 (à paraître).

Gross M. «La fonction sémantique des verbes supports », Travaux de linguistique, $\mathrm{n}^{\circ} 37$, 1998, pp. 25-46.

Grossmann F., Tutin A., «Quelques pistes pour le traitement des collocation», Les collocations : analyse et traitement, Amsterdam, De Werelt, 2003.

Hausmann F. J., «Un dictionnaire des collocations est-il possible ? », Travaux de littérature et de linguistique de l'Université de Strasbourg, 17-1, 1979, pp. 187-195.

Jakobson R., Essais de linguistique générale, Paris, Minuit, 1963.

Lakoff G., Johnson M., Les métaphores dans la vie quotidienne, Paris, Les Editions de Minuit, 1985.

Mel'čuk I., «Collocations: définition, rôle et utilité », Les Collocations : analyse et traitement, 2003, pp. 23-31.

Mel'čuk I., Clas A., Polguère A., Introduction à la lexicologie explicative et combinatoire, Louvain-la-Neuve, Duculot, 1995.

Апресян, Ю. Д. «Английский толково-комбинаторный словарь. I. Лексические функции », Динамические модели: слово, предложение, текст (под ред. Бондарко А. В., Кустовой Г. И., Розиной Р. И.), Москва, Языки славянских культур, 2008, с. 20-58.

Апресян Ю. Д. «О семантической непустоте и мотивированности глагольных лексических функций », Вопросы языкознания, № 4, 2004, с. 3-18.

Арутюнова Н.Д., Предложение и его смысл: логико-семантические проблемы, Москва, URSS, 2009.

Ефремова Т. Ф., Новый словарь русского языка, Москва, Русский язык, 2000.

Иорданская Л. Н., Мельчук И. А., Смысл и сочетаемость в словаре, Москва, Языки славянских культур, 2007.

Ожегов С. И., Словарь русского языка, Москва, Русский язык, 1981.

Падучева Е. В., Статьи разньлх лет, Москва, Языки славянских культур, 2009. 